\title{
Resenha
}

\section{Teoria social cognitiva: conceitos básicos ${ }^{1}$}

\section{Social cognitive theory}

\author{
Elaine Teresinha Dal Mas DIAS²
}

A (re)apresentação da Teoria Social Cognitiva, criada por Albert Bandura, é o reconhecimento da importância de um saber desenvolvido em décadas de pesquisas e estudos por um dos mais significativos e produtivos pensadores da psicologia. Tornar presente esse arcabouço teórico é, a um só tempo, introdução e atualização do conhecimento psicológico.

A proposição primeira desta produção, disposta em oito capítulos, é oferecer parte da conceituação que dá suporte ao pensamento de Bandura, bem como apresentar as origens da Teoria Social Cognitiva e a perspectiva da agência, um de seus fundamentos. Desta forma, a obra possibilita a compreensão do funcionamento humano arraigado em sistemas sociais. E, ainda, dá a conhecer a distinção e as discordâncias de diferentes vertentes teóricas, em especial as teorias behavioristas clássicas e as concepções psicodinâmicas, assim como a diferença das proposições humanistas e existencialistas.

O livro conta com a colaboração de:

- Frank Pajares (Emory University) e Fabián Olaz (Universidad Nacional de Córdoba), que tratam, inicialmente, da compreensão banduriana de indivíduos como seres auto-organizados, pró-ativos, autorreflexivos e autorreguladores, resultado do entrelaçamento dos aspectos pessoais, comportamentais e ambientais.
Posteriormente esses autores apresentam e analisam as relações entre as realizações humanas e as crenças de autoeficácia, que partem da interpretação de quatro princípios originários - experiência de domínio, experiência vicária, persuasões sociais e estados somáticos e emocionais - influenciadores do funcionamento humano.

- Anna Edith Bellico Costa, Universidade Federal de Minas Gerais, que apresenta a modelação como aprendizagem originada em modelos e o papel fundamental na imitação, que pode ter como efeitos a modelação de padrões de respostas, a inibição ou desinibição de respostas aprendidas anteriormente e o estímulo ao desempenho de respostas assemelhadas ao modelo; essa autora ressalta também a relação entre a modelação e o comportamento agressivo presente na sociedade contemporânea.

- Roberta G. Azzi e Soely Polydoro, Universidade Estadual de Campinas, que, além de cuidarem da organização do livro, contextualizam e definem o conceito de autorregulação, estabelecem relações entre autorregulação e influência ambiental e apontam sua aplicabilidade; destacam os trabalhos que envolvem o cotidiano educativo, as situações de mudanças (como a adolescência) e os quadros desviantes.

$\boldsymbol{\nabla \nabla \boldsymbol { \nabla } \nabla}$

1 Bandura, A., Azzi, R. G., \& Polydoro, S. (2008). Teoria social cognitiva: conceitos básicos. Porto Alegre: Artmed.

2 Universidade Nove de Julho, Programa de Mestrado em Educação. Av. Francisco Matarazzo, 612, Água Branca, 05001-000, São Paulo, SP, Brasil. E-mails: <elaine.mas@uninove.br>; <etdmd@terra.com.br>. 
- Fabio Iglesias, Centro Universitário UNIEURO, que discute o desengajamento moral como construção de justificativas de atos, tanto em suas funções inibitórias dos comportamentos antissociais, como nas pró-ativas, consideradas aceitáveis socialmente; esse autor expõe, também, os mecanismos presentes no desengajamento moral.

- Finalmente, A. Bandura participa com quatro artigos - A evolução da teoria social cognitiva, O sistema do selfno determinismo recíproco, A teoria social cognitiva na perspectiva da agência e $O$ exercício da agência humana pela eficácia coletiva.

Os capítulos assinados por Bandura mostram o encadeamento próprio das elaborações teóricas em associação às experiências de vida, que impulsionam e orientam muitas de suas inquietações, principalmente no que concerne à agência humana, que explora, manipula e influencia o ambiente, revelando-se como força de conhecimento que auxilia a explicitação do significado que os sistemas sociais têm em sua obra. Importa destacar a interdependência, a reciprocidade e a recursividade atribuídas aos fatores pessoais e ambientais, em oposição às teorizações fixadas no assujeitamento do comportamento.

A adoção da perspectiva da agência como modelo interativo emergente insere-se na contraposição às leituras parcializadas dos fenômenos comportamentais distanciados da tessitura socioestrutural, que organiza, regula e guia as ações dos homens. A intencionalidade, a antecipação, a autorreatividade e a autorreflexão são apresentadas como características principais da agência.
A Teoria Social Cognitiva segue por dois caminhos distintos: um que procura o esclarecimento dos "mecanismos básicos que governam o funcionamento humano" e outro que busca elucidar o"funcionamento macroanalítico de fatores sociais no desenvolvimento, adaptação e mudança humanos" (Bandura, Azzi \& Polydoro, 2008, p.72). Nesse universo, a modelação social se impõe como fonte de questionamentos e problematizações encaminhadoras de comprovações que justificam e dão corpo aos determinantes e aos mecanismos de atuação.

Destacam-se, na composição desses artigos, a linguagem acessível e inteligível correspondente à exposição e às análises de conceitos básicos que sustentam o posicionamento conceitual. O livro é de interesse também para profissionais de outras áreas do conhecimento, como saúde, educação, psicologia organizacional e do trabalho, por integrar teoria e prática, desvendar a influência das crenças de autoeficácia no desempenho funcional pessoal (na qual prepondera o afetivo sobre o objetivo), apontar a expansão do conhecimento (por intermédio da autorregulação) e indicar as implicações éticas, morais e legais decorrentes do desengajamento moral.

As referências bibliográficas, amplas e diversificadas, possibilitam o aprofundamento e o aprimoramento acerca da Teoria Social Cognitiva, subsidiando a intervenção na realidade.

Recebido em: 29/4/2008

Aprovado em: 28/1/2009 